ПЕТРОСЯНЦ Даниэл Викторович - заместитель руководителя департамента политологии факультета социальныхнаук имассовыхкоммуникаций Финансового университетапри Правительстве РФ (125993, Россия, г. Москва, ГСП-3, Ленинградский пр-кm, 49; dan-basa@yandex.ru)

МИТРАХОВИЧ Станислав Павлович - старший преподаватель департамента политологии факультета социальных наук и массовых коммуникаций Финансового университета при Правительстве РФ (125993, Россия, г. Москва, ГСП-3, Ленинградский пр-кт, 49; stasmitr@mail.ru)

\title{
КОЛЛАБОРАЦИИ В СОВРЕМЕННОЙ НАУКЕ: КУРС НА АВТАРКИЮ?
}

\begin{abstract}
Аннотация. В статье анализируется институт исследовательских научных коллабораций российских ученых, предпринята попытка классификации понятия коллаборации ученых. В работе дается предварительная аналитическая оценка перспектив вступления российских ученых и коллективов ученых в коллаборации с зарубежными учеными и институтами. Авторы стремятся дать ответ на непростые вопросы: как и на каких принципах будут выстраиваться научные коллаборации российских ученых с учеными США, Европейского союза (ЕС), Китая, с учеными и исследователями из других стран.
\end{abstract}

Ключевые слова: научные коллаборации, университеты, исследовательский центр, лаборатория, соавторство, наукометрия

\begin{abstract}
Статья подготовлена по результатам исследований, выполненных за счет бюджетных средств по государственному заданию Финуниверситетуна 2021 г. по теме «Технологические, структурные и социальные факторы долгосрочного экономического роста».
\end{abstract}

Введение. Коллаборации могут носить как спонтанный характер, например группа соратников и единомышленников проводит совместное исследование, так и быть юридически оформленными - национальные образовательные центры (НОЦ), технологические платформы (ТП), двухсторонние договора о сотрудничестве и т.П. Эти исследования могут проводиться как удаленными группами, решающими распределенные научные задачи дистанционно $(G R I D$-системы), так и на основе центров коллективного пользования (ЦКП). Научные коллаборации могут быть как внутристрановыми, так и с участием зарубежных партнеров.

С метрией коллабораций дело обстоит отнюдь не просто, как и с любой оценкой труда ученого. Еще сложнее оценить не только эффективность таких сотрудничеств, но и вообще саму необходимость вступления в коллаборации. Так нужны ли российским ученым коллаборации с зарубежными исследователями? Ответ, на первый взгляд, положительный, а для иллюстрации процитируем блог Александра Краковецкого. На что он сетует? В первую очередь на отсутствие групповой работы. «Сколько людей у нас работают над решением какой-то проблемы? Верно, один. И каждый год все решают одни и те же задачи, или, максимум, ту же задачу, но начинают все с нуля. У нас нет понятия комплексной разработки на уровне кандидатской или докторской работы. Только single разработки. Как можно в одиночку потягаться с Microsoft Research, MIT, Кембриджем или Оксфордом?» Вторая проблема, по мнению автора, отсутствие навыков общения. «Многие из исследователей активно общаются с зарубежными коллегами, я уже не говорю о поездках за границу и обмене опытом? Многие из исследователей никогда не выступали за пределами родного университета, а если и выступали, то это все творилось на уровне 
рисования галочек. Когда человек начинает читать зарубежные труды, то первым его чувством является шок от понимания своей мизерности» 1 .

Другой вопрос, нужны ли зарубежным ученым коллаборации с российскими? Здесь, кажется, также есть перспективы для синергии в сотрудничестве. Однако, чтобы оценить, какие они есть и как будут развиваться, необходимо дать оценку целому ряду факторов и обстоятельств [Салин 2021].

Кто с кем будет вступать в коллаборации? В последнее время все чаще в научной среде задаются вопросами, с какой целью и, самое главное, с какой эффективностью работают научно-исследовательские коллаборации ученых? Понятное дело, что в MegaScience-проектах просто необходимо объединить усилия и перераспределить исследовательские задачи среди группы ученых. Но есть и иной вопрос, насколько ученые разных стран могут быть открытыми и доверять свои интеллектуальные наработки своим зарубежным коллегам, какие полученные знания являются общим достоянием, а какие следует засекретить [Мухаметов 2020]?

18 мая 2021 г. Еврокомиссия представила план международного научно-технологического сотрудничества ${ }^{2}$. В документе детализированы правила взаимодействия с зарубежными странами в области исследований и инноваций. Уходит безвозвратно этика «открытости миру», которой придерживался бывший европейский комиссар по исследованиям и инновациям Carlos Moedas, и на смену ей приходит концепция «открытости для большей части мира».

Также в документе говорится, что «глобальный баланс политической, экономической и культурной власти заметно изменился за последнее десятилетие, отношения между странами быстро меняются из-за растущего влияния стран с экономической и политической системой, основанной на ценностях, сильно отличающихся от европейских, что ставит под сомнение сложившиеся паритеты и догмы о выгодах некоторых научных коллаборационных проектов для ЕС» [Приходько, Каменева 2020]. Сотрудничество отныне будет «выборочным и целевым» - там, где оно оправдано в каждом конкретном случае, при обеспечении взаимности и уважения фундаментальных ценностей ${ }^{3}$.

Этот подход отражает растущую озабоченность политических лидеров в Европе «воровством» интеллектуальной собственности и авторитарным использованием технологий, таких как искусственный интеллект (artificial intelligence) и квантовые технологии (quantum technologies) другими странами, в первую очередь Китаем.

В то же время ЕС стремится возродить глобальные совместные усилия, которые ослабли в последние годы. В частности, будут предприняты шаги, чтобы возродить научные связи по целому ряду проектов в области исследований и инноваций с США в силу дружественных взаимоотношений ЕС с США при президенте Дж. Байдене, что было невозможно при администрации Д. Трампа.

Интересно и то, что ЕС меняет отношение и к дружественным ассоциативным членам своих коллабораций. В частности, он готовится исключить исследователей из Великобритании, Израиля и Швейцарии из крупных проектов квантовых и космических исследований. Это важный шаг, который, по оценке

1 Блог Александра Краковецкого. Доступ: https://habrahabr.ru/post/103150 (проверено 21.07.2021).

2 https://espas.secure.europarl.europa.eu/orbis/topic/eu-global-strategy?page=1 (проверено 11.11.2021).

$3 \mathrm{https}$ ///sciencebusiness.net/news/eu-prepares-new-global-research-vision-fit-post-covidworld (accessed 11.11.2021). 
экспертов, может иметь широкие последствия для научного сотрудничества ЕС с другими странами ${ }^{1}$.

Что же сказано в документе относительно России? Помимо сотрудничества с так называемыми государствами-единомышленниками, существует политически сложная категория «автократических режимов», таких как Россия, которую в проекте аккуратно включают в категорию «другие страны». По крайней мере, в предварительно презентированном документе масштабы исследовательского сотрудничества с Россией невелики. Есть всего одно упоминание России в связи с совместным проектом CREMLIN ${ }^{2}$ программы «Горизонт 2020». Сам проект CREMLIN стартовал еще в 2015 г. и был направлен на развитие международного научно-технического сотрудничества между Россией и ЕС в области исследовательских установок класса MegaScience (исследовательские комплексы мирового уровня). В проекте участвуют НИЦ Курчатовский институт, Институт кристаллографии им. А.В. Шубникова РАН, немецкий синхротронный центр $D E S Y$ и еще 16 крупнейших научно-исследовательских учреждений РФ и ЕС.

Что же касается коллабораций российских ученых с американскими, следует процитировать позицию Министерства энергетики США по научной кооперации: «либо вы работаете на нас, либо на них, если в ней участвуют Россия, Китай, Иран и КНДР». Таким образом, ученые, работающие в США в любой научной лаборатории Минэнерго США, не смогут принимать участие в программах, если выяснится их «причастность» к исследованиям, которые спонсировались этими четырьмя странами. Другие крупнейшие научные организации США придерживаются той же стратегии, хотя и не всегда в столь категоричной форме. Заключенное 13 марта 2019 г. новое соглашение о сотрудничестве между Российской академией наук (РАН) и Национальной академией наук США обозначило круг тем, которых пока не касаются жестко вводимые ограничения. Их немного, точнее, всего две: космос и Арктика.

В США, как и в России, есть несколько источников финансирования науки, но основными являются Национальный фонд научных исследований, Национальный институт здравоохранения, Министерство обороны, Министерство энергетики. Последние два первоначально собирались пожизненно лишить финансирования всех, кто когда-либо участвовал в мегагрантпрограммах Китая, России, Ирана и КНДР³.

Ученые РАН в июне 2018 г. подписали договор о приоритетах в совместных научных исследованиях между Россией и Китаем. К ним относятся: 1) вопросы развития транспортных систем и коридоров; 2) освоение глубоководных ресурсов; 3) совместное строительство и эксплуатация крупных исследовательских объектов (MegaScience) $)^{4}$.

Выводы. Политики на различных уровнях управления наукой обычно поощряют развитие сотрудничества в области исследований. На эти показатели ориентированы и рейтинги университетов. Однако основные детерминанты

1 https://sciencebusiness.net/framework-programmes/news/israel-switzerland-and-uk-faceexclusion-major-eu-quantum-and-space (accessed 11.11.2021).

2 Аббревиатура CREMLIN расшифровывается как Connecting Russian and European Measures for Large-scale research Infrastructures.

3 Война по науке. США открывают новый санкционный фронт. - Коммерсант. Доступ: https://www.kommersant.ru/doc/3894311?fbclid=IwAR1oXsjhHtr8_GANH7VXlcfv9nSdovLdbxR9cfw05CvE-9LeK-f-KaZqp_0 (проверено 11.11.2021).

4 «Новый импульс» в научно-техническом сотрудничестве России и Китая. Информационный портал «Научная Россия». Доступ: https://scientificrussia.ru/articles/brifingprezidenta-ran-s-zhurnalistami (проверено 11.11.2021). 
успешного коллаборационного сотрудничества не очевидны. В частности, в научной литературе почти незаметны исследования, которые, принимая отдельного исследователя в качестве единицы анализа, пытались бы выяснить, может ли сотрудничество именно с иностранными коллегами изменить в сторону успешности научную карьеру конкретного ученого.

\section{Список литературы}

Мухаметов Д.Р. 2020. Политические риски и барьеры цифровизации. Гуманитарные науки. Вестник Финансового университета. Т. 10. № 4. С. 58-64.

Приходько Л.В., Каменева Е.А. 2020. Глобальная конкурентоспособность высшего образования: мировые стратегии и лучшие практики. - Гуманитарные науки. Вестник Финансового университета. Т. 10. № 6. С. 12-18.

Салин П.Б. 2021. Методологические основы политической социализации обучающихся в Российской Федерации иностранных студентов. Гуманитарные науки. Вестник Финансового университета. Т. 11. № 1. С. 72-76.

PETROSYANTS Daniel Viktorovich, Deputy Head of the Department of Political Science, Faculty of Social Sciences and Mass Communications, Financial University under the Government of the Russian Federation (49 Leningradsky Ave, GSP-3, Moscow, Russia, 1259930; dan-basa@yandex.ru)

MITRAHOVICH Stanislav Pavlovich, Senior Lecturer at the Department of Political Science, Faculty of Social Sciences and Mass Communications, Financial University under the Government of the Russian Federation (49 Leningradsky Ave, GSP-3, Moscow, Russia, 1259930; stasmitr@mail.ru)

\section{COLLABORATION IN MODERN SCIENCE: COURSE ON AUTARKY?}

\footnotetext{
Abstract. The article analyzes the institute of research scientific collaborations of Russian scientists; an attempt is made to classify the concept of collaboration of scientists. The paper provides a preliminary analytical assessment of the prospects for the entry of Russian scientists and teams of scientists in collaboration with foreign scientists and institutes. The authors seek to answer difficult questions: how and on what principles scientific collaborations of Russian scientists with US scientists, the European Union (EU), China, with scientists and researchers from other countries will be built.

Keywords: scientific collaborations, universities, research center, laboratory, collaborator, co-authorship, scientometrics
} 